\title{
Population and sustainability
}

Geoffrey McNicoll

Population Council

Follow this and additional works at: https://knowledgecommons.popcouncil.org/departments_sbsr-pgy

Part of the Demography, Population, and Ecology Commons, Environmental Public Health Commons, International Public Health Commons, and the Sustainability Commons

How does access to this work benefit you? Let us know!

\section{Recommended Citation}

McNicoll, Geoffrey. 2005. "Population and sustainability," Policy Research Division Working Paper no. 205. New York: Population Council. 


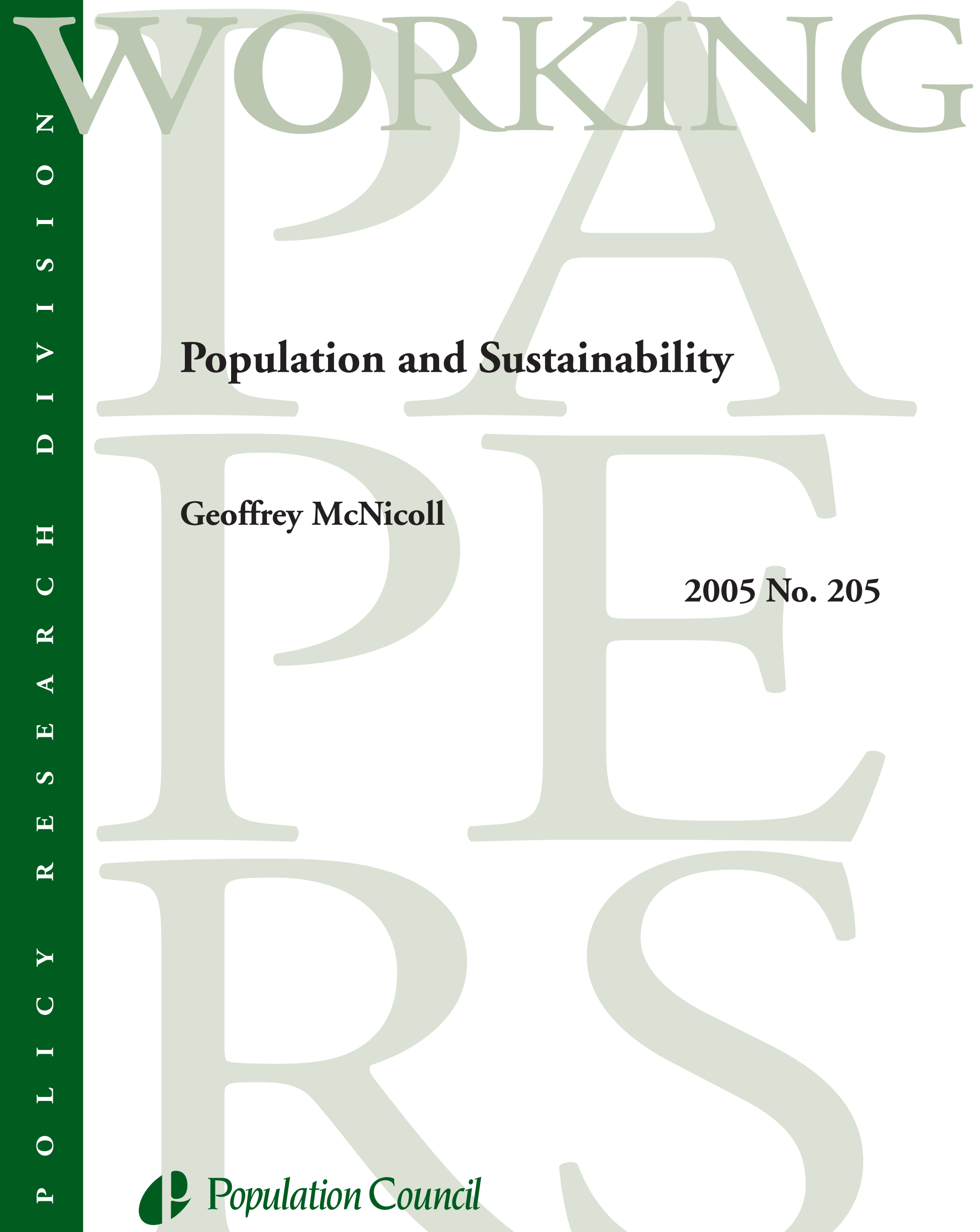




\section{(P) Population Council}

One Dag Hammarskjold Plaza

New York, New York 10017 USA

www.popcouncil.org

pubinfo@popcouncil.org

This material may not be reproduced without written permission from the author. For a list of Policy Research Division Working Papers, including those that are currently available for downloading in PDF format, see www.popcouncil.org/publications/wp/prd/rdwplist.html.

ISSN: $1554-8538$

(C) 2005 The Population Council, Inc. 


\title{
Population and Sustainability
}

\author{
Geoffrey McNicoll
}

Geoffrey McNicoll is Senior Associate, Policy Research Division, Population Council.

Acknowledgments: This work was supported by the Andrew W. Mellon Foundation and the William and Flora Hewlett Foundation.

A version of this paper was prepared as a contribution to the Handbook of Sustainable Development, ed. Giles Atkinson, Simon Dietz, and Eric Neumayer, forthcoming from Edward Elgar, London. 


\begin{abstract}
Sustainability refers to the preservation of human-valued natural capital - the resources that provide environmental services - at a level sufficient to assure the well-being of future generations. Population change bears on sustainability through effects on the total and per capita availability of those services. Possibilities of resource exhaustion are often exaggerated, but so too are the levels of substitutability between natural and other forms of capital. The degradation of environmental services - exemplified by the overuse of aquifers or (at a global level) of the atmospheric carbon sink-is a significant threat to sustainable development, one that is often exacerbated by population growth. The critical management issue in such cases is the design of effective governing institutions to restrain service demand and safeguard supply. Uncertainties arising from nonlinearities and irreversibilities in environmental systems should give pause to expectations that the forecast ending of world population growth, and a subsequent decline in human numbers, will usher in ecological restoration.
\end{abstract}


Problems of sustainability can arise at almost any scale of human activity that draws on natural resources or environmental amenity. In some regions minuscule numbers of hunter-gatherers are thought to have hunted Pleistocene megafauna to extinction; complex preindustrial societies have disappeared, unable to adapt to ecological changes - not least, evidence suggests, changes they themselves wrought (Burney \& Flannery 2005; Janssen \& Scheffer 2004). But modern economic development has brought with it sustainability problems of potentially far greater magnitude - a result not only of the technological capabilities at hand but of the demographic realities of much larger populations and an accelerated pace of change.

A simple picture of those modern realities is seen in Figure 1. It charts a staggered series of population expansions in major world regions since the beginning of the industrial era, attributable to lowered mortality resulting from nutritional improvements, the spread of medical and public health services, and advances in education and income. In each of the regions population growth slows and eventually halts as fertility also drops, completing the pattern known as the demographic transition. The population trajectories shown for the $21 \mathrm{st}$ century are forecasts, of course, but moderately secure ones given improving economic conditions and absent major unforeseen calamities. Worldwide, the medium UN projections foresee world population increasing from its 2005 level of 6.5 billion to a peak of about 9

Figure 1. Population growth in selected countries and regions, $1850-2100$ (estimates and forecasts)

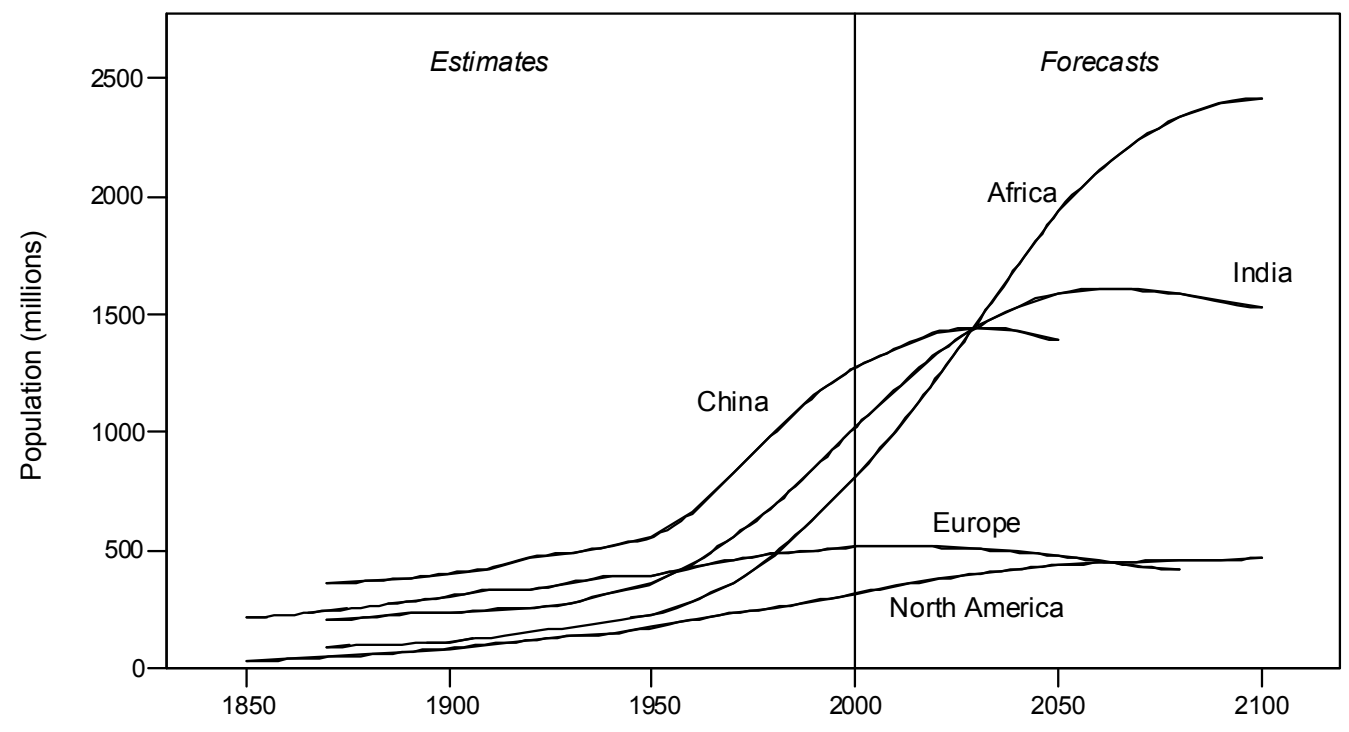

Source of data: Maddison (2003) and United Nations Population Division (medium projections). 
billion around 2075. Very low fertility, if it persists, will lead to actual declines in population size - an all but certain near-term prospect in Europe and a plausible prospect by mid-century in East Asia.

Historically, the increase in population over the course of a country's demographic transition was typically around three- to five-fold, with the pace of change seldom much above 1 percent per year; in the transitions still underway the increases may end up more like ten-fold or even greater and growth rates have peaked well above 2 percent per year. In both situations the size changes are accompanied by shifts in age composition-from populations in which half are aged below 20 years to ones with half over 50 - and in concentrationfrom predominantly rural to overwhelmingly urban. The lagged onset and uneven pace of the transitions across regions generate striking regional differences in population characteristics at any given time. Many population-environment and population-resource issues are thus geographically delimited; for others, however, the scale of environmental spillovers, migration flows, and international trade may require an interregional or global perspective. This chapter reviews the implications of these various features of modern demographic change for sustainable development-gauged in terms of their effects both on the development process and on its outcomes (human well-being and environmental conditions).

The discussion need not be narrowed at the outset by specifying just what sustainable development sustains. The conventional polar choices are the wherewithal needed to assure the welfare of future generations - a generalized notion of capital — and that part of it that is not human-made - what is now usually termed natural capital. Conservation of the former, allowing substitutability among forms of capital, is weak sustainability; conservation of the latter is strong sustainability. (See Norton 1999 and Neumayer 2003 on these concepts and the many problems with them.) I take as a premiss, however, that sustainable development is a topic of interest and importance to the extent that substitutability of natural capital with other kinds of capital in the processes yielding human well-being is less than perfect.

\section{Population AND ResourCes In THE THEORY OF ECONOMIC GROWTH}

For the classical economists, fixity of land was a self-evident resource constraint on the agrarian economies of their day. The course of economic growth was simply described. With expanding (man-made) capital and labour, an initial period of increasing returns, derived from scale economies and division of labour, gave way over time to diminishing returns, eventually yielding a stationary state. To Adam Smith and many others, that notional end point was a bleak prospect: profit-rates dropped toward zero, population growth tailed off, and wages fell to subsistence levels. A very different, more hopeful, vision of stationarity, still in the classical tradition but modern in its view of environmental amenity, was set out by J. S. Mill in a famous chapter (Book IV, chapter 6) of his Principles of Political Economy (1848): population and capital would again have ceased to grow, but earlier in the process and through social choice rather than necessity. Gains in well-being would come from the earlier halting of population growth, and consequent lower populationresource ratios, and from a continuing increase in productivity. A similarly optimistic depiction of a future stationary state-with the "economic problem" solved and human energies diverted to other pursuits — was later drawn by Keynes (1932). 
As technological change increasingly came to be seen as the driver of economic growth, and as urban industrialization distanced most economic activity from the land, theorists of economic growth lost interest in natural resources. With a focus only on capital, labour, and technology, and with constant rates of population growth, savings, and technological change, the models yielded steady-state (and thus, in the model's terms, sustainable) growth paths in which output expanded indefinitely along with capital and labour. More elaborate formulations distinguished among different sectors of the economy. In dualistic growth models, for example, a low-productivity, resource-based agricultural sector provided labour and investment to a dynamic but resource-free modern sector, which eventually dominated the economy. With recognition of nonlinearities associated with local increasing returns and other self-reinforcing mechanisms in the economy, there could be more than one equilibrium growth path, with the actual outcome sensitive to initial conditions or to perhaps fortuitous events along the way (see, for example, Becker et al. 1990; Foley 2000).

Although it typically did not do so, this neoclassical modelling tradition was no less able than its classical forebears to take account of resource constraints. (See Lee 1991 on this point.) Renewable resources would simply add another reproducible form of capital as a factor of production. Non-renewable resources, assuming they were not fully substitutable by other factors and not indefinitely extendable through technological advances, would be inconsistent with any steady-state outcome that entailed positive population growth. Requiring population growth, in the long term, to come to an end is not, of course, a radical demand to make of the theory.

While the actual role of population and resources in economic development is an empirical issue, a lot of the debate on the matter has been based on modelling exercises little more complicated than these. Much of it takes the form of window dressing, tracing out over time the implications of a priori, if often implicit, assumptions about that role. A single assumed functional form or relationship - an investment function, a scale effect, presence (or absence) of a resource constraint - after some initial period comes to dominate the model's behaviour. Familiar examples can be drawn from two models occupying polar positions in the resources debate of the 1970s and 1980s: the model underpinning Julian Simon's The Ultimate Resource (1981) and that supporting the Club of Rome's Limits to Growth scenarios (Meadows et al. 2004). In Simon's case, the existence of resource constraints on the economy is simply denied. Positive feedbacks from a larger population stimulate inventiveness, production, and investment and favor indefinite continuation of at least moderate population growth, leading both to economic prosperity and to vastly expanded numbers of people. (The discussion of the model's output ignores that latter expansion by being couched only in per capita values - see Simon 1977.) For the Meadows team, negative feedback loops working through food production crises and adverse health effects of pollution lead to dramatic population collapses - made even sharper when lagged effects are introduced. Such models, heroically aggregated, are better seen as rhetorical devices, buttresses to qualitative argument, rather than serious efforts at simulation. Their output may point to parts of the formulation that it is important to get right, but does not help in getting it right. While their authors were persuaded that they were accurately portraying the qualitative evidence about population and resources, as they respectively read it, the models in themselves merely dramatized their differences. 
More focussed models can achieve more, if at a lower level of ambition. The demonstration of "trap" situations involving local environmental degradation is a case in point - see Dasgupta (1993). As an example, the PEDA (Population-EnvironmentDevelopment-Agriculture) model developed by Lutz et al. (2002b) describes the interactions among population growth, education, land degradation, agricultural production, and food insecurity. It permits simulation of the vicious circle in which illiteracy, land degradation, and hunger can perpetuate themselves, and points to the conditions required for that cycle to be broken. While still quite stylized, it is cast at a level that permits testing of its behaviour against actual experience, supporting its value for policy experiment.

\section{Optimal Population Trajectories}

Since population change is in some measure a matter of social choice, it can notionally be regarded as a policy variable in a modelling exercise. Varying it over its feasible range then allows it to be optimized for a specified welfare function. The concept of an optimum population size for some designated territory - at which, other things equal, per capita economic well-being (or some other welfare criterion) was maximized - followed as a simple consequence of diminishing returns to labour. A small literature on the subject begins with Edwin Cannan in the late nineteenth century (see Robbins 1927) and peters out with Alfred Sauvy (1952-54) in the mid-twentieth.

This is distinct, of course, from the investigation of human "carrying capacity"—such as the question of how many people the Earth can support. At a subsistence level of consumption some of these numbers are extravagant indeed-Cohen (1995) assembles many of them-but the maximization involved, although in a sense it is concerned with the issue of sustainability, has closer ties to the economics of animal husbandry than to human welfare. (The technological contingency of such calculations is well indicated by the estimate, due to Smil [1991], that fully one-third of the present human population would not exist were it not for the food derived from synthetic nitrogenous fertilizer - a product of the Haber-Bosch process for nitrogen fixation developed only in the early 20th century.) If it is assumed that present-day rich-country consumption patterns are to be replicated worldwide, carrying capacity plummets: for Pimentel et al. (1999) the Earth's long-term sustainability calls for a population less than half its present level.

The question of optimal size also arises for the populations of cities. The urban "built environment," after all, is the immediate environment of half the human population. Beyond some size, scale diseconomies and disamenities deriving from pollution, congestion, and other negative externalities affecting health or livability may eventually outweigh economies of agglomeration (see, for example, Mills \& de Ferranti 1971; Tolley 1974). But other dimensions of the built environment, including its aesthetic qualities, would equally warrant attention in a welfare criterion. Singling out the relationship of population size to the subjective welfare of the average inhabitant, among all the other contributors to urban wellbeing, seems of limited value. Not surprisingly, like the broader topic of optimum population, this too has not proven a fruitful area of research. 
What might be of greater technical interest is the optimal path of population change over time. The age-structure dynamics of population growth are analogous to the vintage dynamics of capital stock, though with more limited scope for policy influence. For specified welfare criteria, optimal population trajectories can be derived to show how resourceconstrained stationarity should be approached. (See Pitchford 1974; Arthur \& McNicoll 1977; Zimmerman 1989.)

Abstract theorizing of this kind is a means of playing with ideas rather than deriving actual policies. Nonetheless, just such an optimization exercise, part static and part dynamic, lay behind the introduction in 1979 of China's radical one-child-per-family policy. The background, recounted by Greenhalgh (2005), was the belated conviction on the part of China's leadership in the 1970s that the country's population growth was damaging its development prospects and the consequent recasting of the problem, as they saw it, from being one for social scientists and political ideologues to one for systems engineers and limits-to-growth theorists. The latter experts were at hand in the persons of a group of engineers and scientists (led by a missile engineer, Song Jian), who became the principals in promoting the new technocratic approach. They investigated both the static optimum - the target population size - and alternative trajectories that would lead toward it. On the former, as they summarized it: "We have done studies based on likely economic development trends, nutritional requirements, freshwater resources, and environmental and ecological equilibrium, and we conclude that 700 million seems to be China's optimum population in the long run" (Song et al. 1985: 214). They then solved the optimal control problem of how fertility should evolve to reach the target population over the next century if the peak population was not to exceed 1.2 billion, there were pre-set constraints on the acceptable lower bound of fertility and upper bound of old-age dependency, and there was to be a smooth transition to the target population while minimizing the total person-years lived in excess of 700 million per year. The resulting policy called for fertility to be quickly brought down to its lower bound, held there for 50 years or so (yielding, after a time, negative population growth), then allowed to rise back to replacement level. While various minimum fertility levels were considered, one child per family was argued to be the best. The human costs of attaining such a trajectory (involving "a lot of unpleasantness in the enforcement of the program"-ibid., p.267) and the social and economic problems of the ensuing rapid population ageing were held to be unavoidable in making up for the "dogged stubbornness of the 1950s" when Maoist pronatalism prevailed (ibid.).

For both countries and cities, the specification of a welfare criterion to be optimized requires decisions on the ingredients of well-being and on how its distribution over the population and over time is to be valued. The inherent arbitrariness of that exercise explains the lack of enthusiasm for the concept of an optimum as a formal construct - though the idea may hold some political potency. Changes in trade and technology-either of which can transform economies of scale-erode what little meaning there is in a static optimum population for a country or locality. A fortiori, the inherent unpredictability of those trends, along with the many unknowns in future environmental change, vitiates the usefulness of more ambitious modelling over time-modelling that has necessarily to assume known dynamics. 
While formal marginalist analysis of population size in complex social systems can thus be regarded as a fairly futile exercise, the broader consideration of societal scale and its effects cannot be similarly dismissed. Indeed it warrants close attention. "For all practical purposes," as Demeny (1986: 487) has remarked, "the population today is much the same as it was yesterday and is barely different from what it will be tomorrow. By those lights, however, we can move, inch by inch, from heaven to hell-or at least from highland to swamp-without noticing it."

\section{EXHAUSTIBLE RESOURCES AND ENVIRONMENTAL SERVICES}

Past worries about rapid or continued population growth have often been linked to the idea that a country-or the world - is running out of some supposedly critical natural resource (see Demeny 1989 for an historical perspective). There have been numerous candidates for those resources in the past. Mostly, such claims have turned out to be greatly overstated; almost always they neglect or underplay the scope for societal adaptation through technological and social change. A classic case was the concern in 19th century Britain that its industry would be crippled as coal supplies were mined out (Jevons 1865). The widelypublicized wagers between economist Julian Simon and biologist Paul Ehrlich on whether stocks of selected mineral resources were approaching exhaustion, to be signalled by steadily rising prices, were all won by Simon as prices fell over the specified period (Simon 1996: 356). A prominent historian of China titled a study of that country's environmental history: "three thousand years of unsustainable development" (Elvin 1993).

Moreover, even if we would accept, contra Simon in The Ultimate Resource, that stocks of many resources are indeed finite and exhaustible, it does not follow that the link to population should necessarily be of much consequence. For those resources, as put bluntly in a 1986 panel report from the US National Research Council, "even if slower population growth does delay the time at which a particular stage of resource depletion is reached,...it has no necessary or even probable effect on the number of people who will live under a particular stage of resource depletion.... Unless one is more concerned with the welfare of people born in the distant future than those born in the immediate future, there is little reason to be concerned about the rate at which population growth is depleting the stock of exhaustible resources" (US National Research Council 1986: 15-16).

But that judgment is altogether too dismissive of the supply problem as a whole. "Mining" a resource that would be potentially renewable, such as a fishery or an aquifer, or degrading land through erosion or salination, may be population-related effects. (The resources allowed as potential sources of concern by the NRC panel were fuelwood, forest

land, and fish; many would add access to fresh water.) These are cases where the concept of a sustainable yield is straightforward enough, but constructing and maintaining the institutional conditions required to safeguard that yield are demanding. Far from a society simply using up one resource and moving on to other things - presumably having replaced that part of its natural capital by other resources or by other forms of capital - the outcome may amount to an effectively irreversible loss in welfare. 
The shift in focus here is from physical "stuff," epitomized by stocks of minerals in the ground, to environmental services that humans draw upon. Environmental services encompass not only provision of food and fuel but also climate regulation, pollination, soil formation and retention, nutrient cycling, and much else. And they include direct environmental effects on well-being through recreation and aesthetic enjoyment. A massive study of time trends in the use of these services, judged against sustainable levels, is the Millennium Ecosystem Assessment. In its first report (2005), the Assessment finds that most of the services it examined are being degraded or drawn on at unsustainable rates. Dryland regions, covering two-fifths of the world's land surface and containing one-third of the world population, are especially affected.

But to what extent can this degradation be linked to population change rather than to economic growth or to the numerous factors that might lead to irresponsible patterns of consumption? People's numbers, but also their proclivities to consume and their exploitative abilities, can all be factors in degrading environmental services. In stylized form, this proposition is conveyed in the familiar Ehrlich-Holdren "IPAT" identity: Impact = Population $\times$ Affluence $\times$ Technology $($ Ehrlich \& Holdren 1972). "Impact" here indicates a persisting rather than transitory environmental effect. It is an external intrusion into an ecosystem which tends to reduce its capacity to provide environmental services. An example of an environmental impact is a country's carbon dioxide emissions, which degrade the environmental service provided by the atmosphere in regulating heat radiation from the earth's surface. The $P \times A \times T$ decomposition in that case would be population times per capita GDP times the "carbon intensity" of the economy. At a given level of affluence and carbon intensity, emissions rise in proportion to population.

Interpreted as a causal relationship rather than as an identity, the $I=P A T$ equation is commonly used to emphasize the responsibility for environmental damage on the part, jointly, of population size, a high-consumption lifestyle, and environmentally-destructive technology, each amplifying the others. Implicitly, it asserts that these factors can together be seen as the main human causes of degradation. The categorization should not, of course, be taken for granted. In particular, social organizational and behavioural factors would often warrant separate scrutiny as causes of degradation rather than being subsumed within $A$ and $T$.

If $P, A$, and $T$ were independent of each other, the multiplicative relationship would be equivalent to an additive relationship among growth rates. In the carbon case, the growth rate of emissions would equal the sum of the growth rates of the three components. However, $P, A$, and $T$ are not in fact independent of each other. For any defined population and environment, they are variables in a complex economic, demographic, and sociocultural system. Each also has major distributional dimensions and is a function of time. Consumption - or any other measure of human welfare - is an output of this system; environmental effects, both intended and unintended, are outputs as well. And even at the global level the system is not autonomous: it is influenced by "natural" changes in the environment and by environmental feedbacks from human activity.

Because of the dependency among $P, A$, and $T$, the Ehrlich-Holdren formula cannot resolve disputes on the relative contributions of factors responsible for environmental degradation. For this task, Preston (1994) has proposed looking at the variances of the growth 
rates of $I, P, A$, and $T$ over different regions or countries. Writing these as $\sigma_{I}^{2}$, etc., the additive relationship among growth rates implies the following relationship among variances and covariances:

$$
\sigma_{I}^{2}=\sigma_{P}^{2}+\sigma_{A}^{2}+\sigma_{T}^{2}+2 \operatorname{cov} P A+2 \operatorname{cov} P T+2 \operatorname{cov}{ }_{A T}
$$

The covariance terms are the interaction effects. If each is relatively small in a given case, there is a simple decomposition of the impact variance into the variance imputed to each factor. Otherwise, the one or more significant interaction terms can be explicitly noted.

In Preston's analysis of carbon emission data for major world regions over 1980-90, used as an illustration, population growth makes a minor contribution to the total variance; the major contributors are the growth of $A$ and $T$, with a substantial offsetting effect from the interaction of $A$ and $T$. Given the 50 percent or so increase in global population projected for this century, the future role of population growth in carbon emissions is nonetheless of some importance. Detailed studies of this relationship include Bongaarts (1992), Meyerson (1998), and O'Neill et al. (2001). Important too, of course, are the demographic consequences of any resulting climate change, such as those working through shifts in food production, disease patterns, and sea levels.

Specification of a more general functional relationship, $I=f(P, A, T)$, permits calculation of impact elasticities with respect to the three factors, rather than implicitly assuming elasticities of 1 . At the country level there is some evidence that the population elasticity is indeed close to 1 for carbon emissions but may be higher for some other pollutants (see Cole and Neumeyer 2004).

Complicating any estimation of population-environment relationships is the nonlinearity of environmental systems. The Millennium Ecosystem Assessment, mentioned above, warns of an increasing likelihood of "nonlinear changes in ecosystems (including accelerating, abrupt, and potentially irreversible changes), with important consequences for human well-being" (2005: 11). Holling (1986) notes that ecosystems may be resilient under the pressure of human activity until a point is reached at which there is sharp discontinuous change. Kasperson et al. (1995) identify a series of thresholds in nature-society trajectories as human activity in a region intensifies beyond sustainability: first a threshold of impoverishment, then endangerment, and finally criticality - the stage at which human wealth and well-being in the region enter an irreparable decline. The working out of the process is detailed in particular settings: criticality is exemplified by the Aral Sea basin. More dramatic historical cases are described by Diamond (2005). Curtailing growth in human numbers may not be a sufficient change to deflect those outcomes, nor may it even be necessary in some circumstances (as discussed below), but population increase has usually been an exacerbating factor.

\section{InSTITUTIONAL Mediation}

Most important links between population and environmental services are institutionally contingent. Under some institutional arrangements - for example, a strong 
management regime, well-defined property rights, or effective community norms and sanctions - population growth in a region need not adversely affect the local environment. Access to a limited resource can be rationed or governed in some other way so that it is not overused. Or the institutional forms may be such that population growth itself is preventedby negative feedbacks halting natural increase (an apparent condition found often in huntergatherer societies) or by diverting the growth elsewhere, through migration. If this institutional mediation ultimately proves inadequate to the task, the limits on the environmental services being drawn on would be exceeded and degradation would ensue. This can happen well short of those limits if economic or political change undermines a management regime, weakens property rights, or erodes norms and sanctions. Excessive deforestation can often be traced to such institutional breakdowns (or to ill-considered efforts at institutional reform) rather than to population growth itself. In other cases, a resource may have been so abundant that no management or sanctions were needed: that is a setting where the familiar "tragedy of the commons" may unfold as the number of claimants to the resource or their exploitative abilities increase (see Hardin 1968).

An appreciable literature now exists on these issues of institutional design, both theoretical and empirical, and ranging in scale from local common-pool resources such as irrigation water or community forests to the global environment (see, for example, Ostrom 1990; Baden \& Noonan 1998). Small common-pool resource systems receive most attention: a favourite example is the experience of Swiss alpine villages, where social regulation limiting overgrazing has been maintained for many generations. Larger systems usually show less symmetry in participant involvement and participant stakes: benefits can be appropriated by favoured insiders, costs shed to outsiders. Judgment of sustainability in such cases may depend on where a system's boundaries are placed, and whether those cost-shedding options can be curtailed (see McNicoll 2002).

Physical spillover effects of human activity beyond the location of that activity, such as downwind acid rain from industrial plants or downstream flooding caused by watershed destruction, present relatively straightforward technical problems for design of a governance regime. The greater difficulties are likely to be political. These can be formidable even within a country, a fortiori where the environmental effects involve degradation of a global commons. Population change here raises added complications. Thus, in negotiating a regulatory regime to limit global carbon emissions, anticipated population growth in a country can be treated either as a foreordained factor to be accommodated by the international community - occasioning a response analogous to political redistricting in a parliamentary democracy_or treated wholly as a domestic matter (an outcome of social policy) that should not affect assignment of emission quotas.

Adverse effects of human activity can also be transferred from one region to another through the normal economic relationships among societies, notably through trade. A poorer society may be more willing to incur environmental damage in return for economic gain, or be less able to prevent it. The concept of a community's "ecological footprint" was developed to account for such displaced effects by translating them back into material terms, calculating the total area required to sustain each community's population and level of consumption (see Wackernagel \& Rees 1996, and, for criticism, Neumayer 2003). An implicit presumption of environmental autarky would disallow rich countries' buying renewable resources from poor 
countries; notionally, if implausibly, they could maintain their consumption by somehow reducing their population.

\section{Population Ageing and Population Decline}

As noted earlier, the age composition of populations that emerge from the transition to low mortality and fertility are heavily weighted toward the elderly, and after transitional effects on the age distribution have worked themselves out, actual declines in population numbers are likely. For example, if fertility were to stay at the current European average of around 1.4 lifetime births per woman ( 0.65 births below the replacement level), each generation will be about one-third smaller than its predecessor. Change of that magnitude could not be offset by any politically feasible level of immigration.

After the ecological damage associated with industrialization, it might be expected that the ending of the demographic transition would have positive effects on sustainability. There are fewer additional people, or even fewer people in total, and those there are will mostly live compactly in cities and have the milder and perhaps more environmentallyfriendly consumption habits of the elderly. There may be scope for ecological recovery. In Europe, for instance, the evidence suggests that a strong expansion in forested area is occurring as land drops out of use for cultivation and grazing (Waggoner \& Ausubel 2001). The so-called environmental Kuznets curve - the posited inverted-U relationship between income and degradation - gives additional grounds for environmental optimism since posttransition societies are likely to be prosperous. But there are countervailing trends as well. Household size tends to diminish, for example, and small households, especially in sprawling suburbs, are less efficient energy users (see O'Neill \& Chen 2002). Moreover, ecosystem maintenance increasingly calls for active intervention rather than simply halting of damage. Mere neglect does not necessarily yield restoration. Many human-transformed landscapes that have valued productive or amenity qualities similarly require continuing maintenance. Expectations of strengthened environmentalism around the world may not be borne outpreferences, after all, tend to adapt to realities - and even a strong environmental ethic is powerless in the face of irreversibilities.

Population decline, of course, can come about for reasons other than post-transition demographic maturity: from wars or civil violence and natural disasters, and (a potentially larger demographic threat) from epidemic disease (see Smil 2005). These events too have implications for sustainability, at least locally. Their effect is magnified to the degree they do harm to the productive base of the economy (including its natural resource base) and to the social institutions that maintain the coherence of a society over time.

\section{RESEARCH DIRECTIONS}

Much of the research that would shed light on demographic aspects of sustainability is best covered under the general heading of sustainable development. This is largely true for the long-run changes that constitute the demographic transition. To a considerable degree the

transition is neither an autonomous process nor policy-led, but a byproduct of economic and 
cultural change, and it is this latter that should be the research focus. For example, in studies of rainforest destruction - a standard illustration of adverse demographic-cum-development impact on the environment - a basic characteristic of the system is precisely its demographic openness. Demographic "pressure" supposedly leads to land clearing for pioneer settlement, but a broader research perspective would investigate the economic incentives favouring that kind of settlement over, say, cityward migration (Brazil's rural population in 2005 was onethird smaller than its 1970 peak). As to policy influence, migration and fertility might be seen as potential candidates to be demographic control variables in a population-economyenvironment system, but even if they technically lie within a government's policy space, aside from cross-border movement most governments have very limited if any direct purchase over them.

While there may thus be less content in population and sustainability than first appears, an important research agenda remains. A critical subject, signalled above, is the design of governing institutions for population-economy-environment systems, able to ensure sustainable resource use. Those institutions are of interest at a range of system levels-local, national, and international - and are likely to entail intricate combinations of pricing and rationing systems and means of enforcement. At the local level, and possibly at other levels too, governing institutions might seek to include measures aiming at the social control of population growth.

A less elusive but similarly important research area concerns demographic effects on consumption. How resource- and energy-intensive will the consumption future be, given what we know about the course of population levels and composition? How do we assess substitutability in consumption - say, between "real" and "virtual" environmental amenity? And, well beyond the demographic dimension but still informed by it, are we, in confronting sustainability problems, dealing with time-limited effects of a population peaking later this century (with an additional 2-3 billion people added to the world total) but then dropping, allowing some measure of ecological recovery, or are we entering a new, destabilized environmental era in which sustainability in any but the weakest sense is continually out of reach? 


\section{REFERENCES}

Arthur, W. Brian and Geoffrey McNicoll. 1977. Optimal growth with age dependence: a theory of population policy. Review of Economic Studies 44 (1): 111-123.

Baden, John A. and Douglas S. Noonan (eds.) 1998. Managing the Commons. 2nd ed. Bloomington, IN: Indiana University Press.

Becker, Gary S., Kevin M. Murphy, and Robert Tamura. 1990. Human capital, fertility, and economic growth. Journal of Political Economy 98: S12-S37.

Bongaarts, John. 1992. Population growth and global warming. Population and Development Review 18: 299-319.

Burney, D.A. and T.F. Flannery. 2005. Fifty millennia of catastrophic extinctions after human contact. Trends in Ecology \& Evolution 20: 395-401.

Cohen, Joel. 1995. How Many People Can the Earth Support? New York: Norton.

Cole, Matthew A. and Eric Neumayer. 2004. Examining the impact of demographic factors on air pollution. Population and Environment 26: 5-21.

Dasgupta, Partha. 1993. An Inquiry into Well-Being and Destitution. Oxford: Clarendon Press.

Demeny, Paul. 1986. Population and the invisible hand. Demography 23: 473-487.

Demeny, Paul. 1989. Demography and the limits to growth. In Michael S. Teitelbaum and Jay M. Winter (eds.), Population and Resources in Western Intellectual Traditions. Supplement to Population and Development Review. New York: Population Council.

Diamond, Jared. 2005. Collapse: How Societies Choose to Fail or Succeed. New York: Penguin.

Ehrlich, Paul R. and John P. Holdren. 1972. One-dimensional ecology. Bulletin of the Atomic Scientists 28 (June): 16-27.

Elvin, Mark. 1993. Three thousand years of unsustainable development: China's environment from archaic times to the present. East Asian History (Canberra) No. 6.

Foley, Duncan K. 2000. Stabilization of human populations through economic increasing returns. Economic Letters 68: 309-317.

Greenhalgh, Susan. 2005. Missile science, population science: the origins of China's onechild policy. China Quarterly No. 182: 253-276.

Hardin, Garrett S. 1968. The tragedy of the commons. Science 162: 1243-1248.

Holling, C. S. 1986. The resilience of terrestrial ecosystems: local surprise and global change. In William C. Clark and R. E. Munn (eds.) Sustainable Development of the Biosphere. Cambridge: Cambridge University Press.

Janssen, Marco A. and Marten Scheffer. 2004. Overexploitation of renewable resources by ancient societies and the role of sunk-cost effects. Ecology and Society 9 (1): 6. [online] URL: http://www.ecologyandsociety.org/vol9/iss1/art6/ 
Jevons, W. Stanley. 1865. The Coal Question: An Enquiry Concerning the Progress of the Nation, and the Probable Exhaustion of Our Coal-mines. London: Macmillan.

Kasperson, Jeanne X., Roger E. Kasperson, and B.L. Turner II (eds.) 1995. Regions at Risk: Comparisons of Threatened Environments. Tokyo: United Nations University Press.

Keynes, John Maynard. 1932. Economic possibilities for our grandchildren. In his Essays in Persuasion. London: Macmillan.

Lee, Ronald D. 1991. Comment: the second tragedy of the commons. In Kingsley Davis and Mikhail S. Bernstam (eds.), Resources, Environment, and Population: Present Knowledge, Future Options. New York: Oxford University Press.

Lutz, Wolfgang, Alexia Prskawetz, and Warren C. Sanderson (eds.) 2002a. Population and Environment: Methods of Analysis. Supplement to Population and Development Review. New York: Population Council.

Lutz, Wolfgang, et al. 2002b. Population, natural resources, and food security: lessons from comparing full and reduced-form models. In Lutz, Prskawetz, and Sanderson (2002a).

Maddison, Angus. 2003. The World Economy: Historical Statistics. Paris: Organisation for Economic Co-operation and Development.

McNicoll, Geoffrey. 2002. Managing population-environment systems: problems of institutional design. In Lutz, Prskawetz, and Sanderson (2002a).

Meadows, Donella, Jorgen Randers, and Dennis Meadows. 2004. The Limits to Growth: The 30-year Update. White River Junction, VT: Chelsea Green.

Meyerson, Frederick A. B. 1998. Population, carbon emissions, and global warming: the forgotten relationship at Kyoto. Population and Development Review 24: 115-130.

Mill, John Stuart. 1848. Principles of Political Economy. London: Parker.

Millennium Ecosystem Assessment. 2005. Ecosystems and Human Well-Being: Synthesis. New York: Island Press.

Mills, Edwin S. and David M. de Ferranti. 1971. Market choices and optimum city size. American Economic Review 61 (Papers \& Proceedings): 340-345.

Neumayer, Eric. 2003. Weak versus Strong Sustainability: Exploring the Limits of Two Opposing Paradigms. 2nd ed. Cheltenham, UK: Elgar.

Norton, Bryan. 1999. Ecology and opportunity: intergenerational equity and sustainable options. In Andrew Dobson (ed.), Fairness and Futurity: Essays on Environmental Sustainability and Social Justice. Oxford: Oxford University Press.

O'Neill, Brian C. and Belinda S. Chen. 2002. Demographic determinants of household energy use in the United States. In Lutz, Prskawetz, and Sanderson (2002a).

O'Neill, Brian C., F. Landis MacKellar, and Wolfgang Lutz. 2001. Population and Climate Change. Cambridge: Cambridge University Press.

Ostrom, Elinor. 1990. Governing the Commons: The Evolution of Institutions for Collective Action. Cambridge: Cambridge University Press. 
Pimental, David, et al. 1999. Will limits of the Earth's resources control human numbers? Environment, Development and Sustainability 1: 19-39.

Pitchford, J. D. 1974. Population in Economic Growth. New York: Elsevier.

Preston, Samuel H. 1994. Population and Environment: From Rio to Cairo. Liège: International Union for the Scientific Study of Population.

Robbins, Lionel. 1927. The optimum theory of population. In London Essays in Economics in Honour of Edwin Cannan, ed. T. E. Gregory and Hugh Dalton. London: Routledge.

Sauvy, Alfred. 1952-54. Théorie générale de la population. Paris: Presses Universitaires de France. 2 vols. (Translated as General Theory of Population. New York: Basic Books, 1969.)

Simon, Julian L. 1977. The Economics of Population Growth. Princeton: Princeton University Press.

Simon, Julian S. 1996, 2nd ed. 1st ed., 1981. The Ultimate Resource. Princeton: Princeton University Press.

Smil, Vaclav. 1991. Population growth and nitrogen: an exploration of a critical existential link. Population and Development Review 17: 569-601.

Smil, Vaclav. 2005. The next 50 years: fatal discontinuities. Population and Development Review 31: 201-236.

Song, Jian, Chi-Hsien Tuan, and Jing-Yuan Yu. 1985. Population Control in China: Theory and Applications. New York: Praeger.

Tolley, George S. 1974. The welfare economics of city bigness. Journal of Urban Economics 1: 324-345.

US National Research Council. 1986. Population Growth and Economic Development: Policy Questions. Washington, DC: National Academy Press.

Wackernagel, Mathis and William E. Rees. 1996. Our Ecological Footprint: Reducing Human Impact on the Earth. Philadelphia: New Society Publishers.

Waggoner, Paul E. and Jesse H. Ausubel. 2001. How much will feeding more and wealthier people encroach on forests? Population and Development Review 27: 239-257.

Zimmermann, Klaus F., ed. 1989. Economic Theory of Optimal Population. Berlin: SpringerVerlag. 


\section{POLICY RESEARCH DIVISION WORKING PAPERS}

If still in print, single copies of up to three working papers from 1989 through 2003 are available free of charge.

Beginning with the 2004 issues, working papers are no longer available in print format. Instead they are distributed electronically. As each new paper is completed subscribers are notified by e-mail and a link to the paper is provided.

To subscribe to the Policy Research Division working paper e-mail notification list, or to obtain back issues from 1989 to 2003, please send your request to prdwp@popcouncil.org.

PDFs of recent issues are available at www.popcouncil.org/publications/wp/prd/rdwplist.html

2005

205 Geoffrey McNicoll, "Population and sustainability."

204 John Bongaarts, "The causes of stalling fertility transitions."

203 Ayaga A. Bawah and Fred N. Binka, "How many years of life could be saved if malaria were eliminated from a hyperendemic area of northern Ghana?"

202 Barbara S. Mensch, Susheela Singh, and John B. Casterline, "Trends in the timing of first marriage among men and women in the developing world."

201 Zachary Zimmer, "Active life expectancy and functional limitations among older Cambodians: Results from a 2004 survey."

200 Brian Wells Pence, Philomena Nyarko, James F. Phillips, and Cornelius Debpuur, "The effect of community nurses and health volunteers on child mortality: The Navrongo Community Health and Family Planning Project."
199 Zachary Zimmer, Linda G. Martin, Mary Beth Ofstedal, and Yi-Li Chuang, "Education of adult children and mortality of their elderly parents in Taiwan."

198 Mian Bazle Hossain, James F. Phillips, and Thomas K. LeGrand, "The impact of childhood mortality on fertility in six rural thanas of Bangladesh."

197 Kristine R. Baker, Mary Beth Ofstedal, Zachary Zimmer, Zhe Tang, and Yi-Li Chuang, "Reciprocal effects of health and economic well-being among older adults in Taiwan and Beijing."

196 Mark R. Montgomery and Paul C. Hewett, "Poverty and children's schooling in urban and rural Senegal."

195 Luciana Suran, Sajeda Amin, Lopita Huq, and Kobita Chowdury, "Does dowry improve life for brides? A test of the bequest theory of dowry in rural Bangadesh." 
194 Barbara S. Mensch, Monica J. Grant, Mary P. Sebastian, Paul C. Hewett, and Dale Huntington. "The effect of a livelihoods intervention in an urban slum in India: Do vocational counseling and training alter the attitudes and behavior of adolescent girls?"

193 Amanda Ritchie, Cynthia B. Lloyd, and Monica Grant. "Gender differences in time use among adolescents in developing countries: Implications of rising school enrollment rates."

192 John Bongaarts. "Long-range trends in adult mortality: Models and projection methods."

191 John Koku Awoonor-Williams, Ellie S. Feinglass, Rachel Tobey, Maya N. Vaughan-Smith, Frank K. Nyonator, Tanya C. Jones, and James F. Phillips, "Bridging the gap between evidence-based innovation and national healthsector reform in Ghana."

190 Kelly Hallman, "Socioeconomic disadvantage and unsafe sexual behaviors among young women and men in South Africa."

189 Toshiko Kaneda, Zachary Zimmer, and Zhe Tang, "Differentials in life expectancy and active life expectancy by socioeconomic status among older adults in Beijing."

188 Cynthia B. Lloyd and Monica J. Grant, "Growing up in Pakistan: The separate experiences of males and females."
187 Zachary Zimmer, Xianghua Fang, Toshiko Kaneda, Zhe Tang, and Julia Kwong. "Trends and transitions in children's coresidence with older adults in Beijing municipality."

186 Sajeda Amin and Alaka M. Basu. "Popular perceptions of emerging influences on mortality and longevity in Bangladesh and West Bengal."

185 John Bongaarts. "Population aging and the rising cost of public pensions."

184 Mark R. Montgomery and Paul C. Hewett. "Urban poverty and health in developing countries: Household and neighborhood effects.

2003

183 Agnes R. Quisumbing and Kelly Hallman. "Marriage in transition: Evidence on age, education, and assets from six developing countries."

182 Paul C. Hewett, Barbara S. Mensch, and Annabel S. Erulkar, "Consistency in the reporting of sexual behavior among adolescent girls in Kenya: A comparison of interviewing methods."

181 Zachary Zimmer, Linda G. Martin, and Hui-Sheng Lin, "Determinants of old-age mortality in Taiwan." 
180 Frank K. Nyonator, J. Koku Awoonor-Williams, James F. Phillips, Tanya C. Jones, and Robert A. Miller, "The Ghana Community-based Health Planning and Services Initiative: Fostering evidence-based organizational change and development in a resourceconstrained setting."

179 John Bongaarts and Griffith Feeney, "Estimating mean lifetime."

178 Elizabeth F. Jackson, Patricia Akweongo, Evelyn Sakeah, Abraham Hodgson, Rofina Asuru, and James F. Phillips, "Women's denial of having experienced female genital cutting in northern Ghana: Explanatory factors and consequences for analysis of survey data."

177 John Bongaarts, "Completing the fertility transition in the developing world: The role of educational differences and fertility preferences."

176 Cynthia B. Lloyd and Paul C. Hewett, "Primary schooling in sub-Saharan Africa: Recent trends and current challenges."

175 James F. Phillips, Tanya C. Jones, Frank K. Nyonator, and Shruti Ravikumar, "Evidence-based development of health and family planning programs in Bangladesh and Ghana."

174 Geoffrey McNicoll, "Population and development: An introductory view."
173 Paul Demeny, "Population policy: A concise summary."

172 Zachary Zimmer, Napaporn Chayovan, Hui-Sheng Lin, and Josefina Natividad, "How indicators of socioeconomic status relate to physical functioning of older adults in three Asian societies."

171 Sajeda Amin and Nagah H. AlBassusi, "Wage work and marriage: Perspectives of Egyptian working women."

170 Ravai Marindo, Steve Pearson, and John B. Casterline, "Condom use and abstinence among unmarried young people in Zimbabwe: Which strategy, whose agenda?"

169 Zachary Zimmer and Julia Dayton, "The living arrangements of older adults in sub-Saharan Africa in a time of HIV/AIDS."

168 Paul C. Hewett, Annabel S. Erulkar, and Barbara S. Mensch, "The feasibility of computerassisted survey interviewing in Africa: Experience from two rural districts in Kenya." 